\title{
PENGARUH VOLUME AIR DI RUANG MUAT TERHADAP STABILITAS KAPAL PENGANGKUT IKAN HIDUP
}

\author{
The Effect of Amount of Water Volume in the Load Space on the Stability \\ of the Vessels Carrying Live Fish
}

\author{
Randy Hedva Rakasiwi Rumbawa ${ }^{1}$, Ali Azhar ${ }^{1, *}$ dan Kusnindar Priohutomo \\ ${ }^{1}$ Teknik Perkapalan, Universitas Hang Tuah \\ Jl. Arief Rahman Hakim No.150, Surabaya, Indonesia \\ ${ }^{2}$ Balai Teknologi Hidrodinamika, Badan Pengkajian dan Penerapan Teknologi \\ Jl. Hidrodinamika BPPT, Kompleks ITS, Surabaya, Indonesia \\ e-mail:" ${ }^{2}$ ali.azhar@hangtuah.ac.id
}

\begin{abstract}
Abstrak
Kapal pengangkut ikan hidup merupakan salah satu alat transportasi yang digunakan selama proses ekspor maupun domestik dan bertujuan untuk mempertahankan ikan dalam keadaan tetap hidup. Muatan utama kapal pengangkut ikan hidup (KPIH) adalah air dan ikan yang berenang bebas di dalamnya dan muatan cair dalam ruang muat dapat bergerak bebas, sehingga terjadi free surface effect (FSE). Paper ini bertujuan untuk menghitung dan mensimulasikan stabilitas kapal pengangkut ikan hidup dan muatan berupa cairan, sehingga dapat diketahui stabilitas kapal berdasarkan muatannya. Analisa stabilitas berdasarkan variasi muatan menggunakan software Maxsurf. Hasil dari analisa stabilitas berdasarkan variasi muatan pada ruang muat $0 \%$, $25 \%, 50 \%, 75 \%, 95 \%$ dengan variasi volume FOT dan FWT 25\%, 50\%, 75\%, 100\% adalah stabilitas kapal tidak layak untuk FOT dan FWT $\leq 75 \%$ menurut kriteria IMO.
\end{abstract}

Kata kunci: kapal pengangkut ikan hidup; stabilitas kapal; free surface effect; muatan kapal

\section{Abstract}

The vessels carrying live fish are one of the means of transportation used for the export and domestic processes, and it aims at keeping fish alive. The main loads of these vessels are living fish and water, so the fish can be freely to swim inside the vessel. Therefore, it forms a free surface effect (FSE). This paper aimed at calculating and simulating the stability of the vessels carrying live fish which the cargo on the vessel are liquid, so that the stability of the ship can be determined based on its loads, water and living fish. The stability analysis was based on loads variation using Maxsurf Software, so the results obtained were apt with the criteria set by IMO. The results of the stability analysis based on the load variations in the cargo hold were 0\%, 25\%, 50\%, 75\%, 95\%, and the load variations of fresh water tank and fuel oil tank were 25\%,50\%, 75\%, 100\%. Based on the results of the simulation it was concluded that ships with FWT and FOT load volumes were less than $75 \%$ hence vessel stability criteria did not meet IMO standards.

Keywords: vessels carrying live fish; ship stability; free surface effect, ship load 


\section{PENDAHULUAN}

Pengangkutan ikan dengan sistem tertutup hakekatnya dapat mengurangi volume dan berat air pada pengangkutan, sehingga memungkinkan untuk mengangkut ikan dalam jangka waktu pengangkutan yang lebih lama dan secara ekonomis menguntungkan (Kusyairi dkk., 2013) dimana pengangkutan ini dapat menggunakan berbagai moda transportasi yang salah satunya menggunakan kapal.

Kapal pengangkut ikan hidup merupakan alat transportasi yang digunakan selama proses ekspor maupun domestik, bertujuan untuk mempertahankan ikan dalam keadaan tetap hidup. Kapal pengangkut ikan hidup termasuk kapal pengangkut ikan, dan muatan utama kapal pengangkut ikan hidup (KPIH) adalah air dan ikan yang berenang bebas di dalamnya. Oleh karena itu, maka jenis muatan di dalam palka KPIH adalah merupakan muatan jenis liquid (cair) (Novita, 2011).

Muatan cair merupakan muatan yang dapat mudah untuk berubah bentuk, oleh karena itu pada tangki atau palka yang berisi muatan cairan agar menghindari adanya ruang bebas antara permukaan cairan dengan tutup atau dinding di atasnya (face surface). Kondisi ini dimaksudkan agar stabilitas kapal tidak terganggu akibat adanya efek free surface muatan cair yang berada di dalam tangki atau palka.

Kapal pengangkut ikan hidup tidak didesain untuk mengangkut muatan ikan saja, melainkan juga mengangkut air yang dapat mempertahankan ikan dalam keadaan hidup sehingga menjaga kualitas ikan tersebut. Pada saat kapal pengangkut ikan hidup melakukan loading, muatan tersebut tidak sesuai dengan kapasitas penuh dari ruang muat. Sehingga muatan ikan dan jumlah volume air di ruang muat kapal pengangkut ikan hidup tidak selalu sama dan sarat kapal harus diperhatikan.

Stabilitas merupakan kemampuan bagian lambung kapal yang tercelup sebagian atau keseluruhan untuk mengapung tegak lurus, ketika kehilangan keseimbangan kapal mampu kembali pada posisi tegak lurus setelah penyebab kemiringan hilang. Perhitungan stabilitas dapat digunakan untuk mengetahui kemampuan kapal kembali pada posisi tegak lurus apabila mengalami oleng pada saat berlayar. Kapal harus mempunyai stabilitas yang baik dan harus mampu menahan semua gaya luar yang mempengaruhinya hingga kembali pada keadaan seimbang. Istilah penting dalam perhitungan stabilitas kapal yaitu:

\section{- Titik berat $(\mathrm{G})$}

Titik berat atau center of gravity atau biasa dikenal dengan titik $G$ pada sebuah kapal merupakan titik tangkap dari semua gaya-gaya yang menekan ke arah bawah kapal. Letak titik $\mathrm{G}$ dapat diketahui melalui pembagian tata letak muatan. Semakin banyak muatan yang diletakkan di bagian atas kapal maka letak titik $\mathrm{G}$ akan semakin tinggi. Sebaliknya jika muatan banyak yang diletakkan di bagian bawah geladak kapal maka posisi titik $G$ semakin rendah. Sehingga dapat disimpulkan titik $G$ ini tidak akan berubah letaknya selama tidak ada pegeseran/perpindahan muatan sekalipun kapal dalam keadaan miring atau oleng.

- Titik apung (B)

Titik apung atau center of bouyance atau biasa dikenal dengan titik B pada sebuah kapal merupakan titik tangkap dari semua gaya-gaya yang menekan ke arah atas kapal. Titik B ini juga letaknya dapat berpindah-pindah sesuai dengan adanya perubahan sarat kapal. Dalam stabilitas kapal titik B yang menyebabkan kapal dapat kembali ke kondisi tegak kembali setelah mengalami oleng.

- Titik metasentris (M)

Titik metasentris atau biasa dikenal dengan titik M pada sebuah kapal adalah titik semua sebagai batas dimana titik $\mathrm{G}$ tidak boleh melewati di atasnya agar kapal mempunyai stabilitas positif. Letak titik M ini juga berubah- ubah sesuai dengan sudut keolengan kapal.

Banyak penelitian yang membahas tentang stabilitas kapal antara lain paper yang ditulis oleh (Novita dkk., 2014) dimana dijelaskan muatan liquid di dalam palka KPIH masih dapat bergerak bebas dikarenakan permukaannya tidak dibatasi. Oleh karena itu, pada saat kapal melakukan gerakan oleng, maka permukaan muatan liquid tersebut akan bebas bergerak ke arah kemiringan kapal selama terjadinya 
gerakan oleng kapal. Jika massa air yang bergerak ke arah kemiringan kapal saat kapal oleng berlebihan, maka titik berat muatanpun akan bergeser ke arah kemiringan kapal. Perpindahan titik berat muatan akan mempengaruhi stabilitas kapal.

Paper berikutnya yang ditulis oleh (Ananda, 2017), yang membahas tentang adanya kapal pengangkut ikan hidup, ikan dapat diekspor dalam keadaan hidup dan bernilai tinggi. Diperlukan sistem transportasi ikan yang tepat agar kualitas ikan terjaga sampai di konsumen dengan cara mendesain sistem pengangkutan ikan hidup dan menggunakan palka ikan hidup dengan sistem tertutup.

Paper lain yang membahas tentang stabilitas kapal ditulis oleh (Mujahid dan Priohutomo, 2018) yang mengkaji tentang analisa stabilitas dan perhitungan tegangan geser pada kapal hisap tambang dengan teknologi Bore Hole Mining (BHM) dimana kapal BHM adalah kapal yang khusus digunakan untuk eksplorasi mineral bebatuan di laut. Pada paper ini menjelaskan tentang stabilitas kapal pada kondisi loadcase departure, loadcase full load, loadcase half load dan loadcase arrival . Kesimpulan dari paper ini adalah kapal BHM tidak memenuhi standar yang ditetapkan oleh IMO pada kondisi $25 \mathrm{deg}$.

Paper berikutnya adalah yang ditulis oleh (Waluyo dkk., 2018) yang mengkaji tentang karakteristik sea keeping Kapal Angkut Ikan 60 GT di sebaran wilayah perikanan perairan Indonesia dimana pada kondisi kapal berhadapan dengan gelombang (beam seas) 90 deg. merupakan kondisi yang secara umum perlu diwaspadai pada kapal karena berpengaruh pada mode gerak roll sangat signifikan terkait stabilitas kapal. Kesimpulan dari paper ini adalah pada perubahan arah dan kecepatan kapal sangat diperlukan untuk memperbaiki tingkat roll kapal yang lebih baik dan juga perlu dipertimbangkan operasional lapangan dan pola gerak kapal terkait muatan ikan curah yang diangkut kapal tersebut.

Paper lain adalah yang ditulis oleh (Kristiyono dan Azhar, 2017) yang telah membahas tentang kajian eksperimental stabilitas kapal kecil di Lamongan dengan metode rolling period test yang sesuai dengan prosedur pada kapal Tria Jaya di Pelabuhan TPI Kranji Lamongan. Hasil dari paper ini adalah Kapal Tria Jaya memiliki nilai GM kurang dari $0,35 \mathrm{~m}$ dimana nilai ini belum sesuai atau belum masuk pada batas yang ditetapkan oleh Germanischer Llyod (GL) untuk kapal dengan ukuran kurang dari $24 \mathrm{~m}$.

Berdasarkan latar belakang tersebut, maka penulis melakukan kajian untuk mengetahui pengaruh jumlah volume air terhadap stabilitas kapal pengangkut ikan. Sehingga dapat diketahui seberapa besar perbandingan antara jumlah volume air pada ruang muat yang berpengaruh terhadap stabilitas kapal.

\section{METODE}

\section{Ukuran Utama Kapal}

Salah satu hal penting di dalam perhitungan nilai stabilitas adalah ukuran utama kapal yang akan dihitung. Dimana pada paper ini ukuran utama menggunakan data penelitian yang ditulis oleh (Ananda, 2017) yang ditampilkan pada Tabel 1.

Tabel 1. Data utama kapal

\begin{tabular}{ccc}
\hline Keterangan & Nilai & Satuan \\
\hline LPP & 30,6 & $\mathrm{~m}$ \\
$\mathrm{~B}$ & 7,5 & $\mathrm{~m}$ \\
$\mathrm{H}$ & 5,7 & $\mathrm{~m}$ \\
$\mathrm{~T}$ & 4,2 & $\mathrm{~m}$ \\
Displacement & 300 & $\mathrm{GT}$ \\
Vs & 14 & $\mathrm{knot}$ \\
\hline
\end{tabular}

\section{Pemodelan Lambung Kapal}

Setelah data utama didapatkan, maka langkah selanjutnya adalah melakukan modelling lambung kapal menggunakan perangkat lunak/software untuk mendesain kapal yaitu software Maxsurf Modeling. Model kapal digambar sesuai dengan gambar dari general arragement (GA) pada penelitian (Ananda, 2017) yang ditampilkan pada Gambar 1. Dari data GA tersebut dapat dibuat model kapal dalam bentuk 
tiga dimensi (3D) yang nantinya akan digunakan untuk perhitungan letak tangki pada kapal tersebut. Untuk gambar 3D hasil penggambaran menggunakan
Maxsurf Modeler ditampilkan pada Gambar 2 dan Gambar 3.

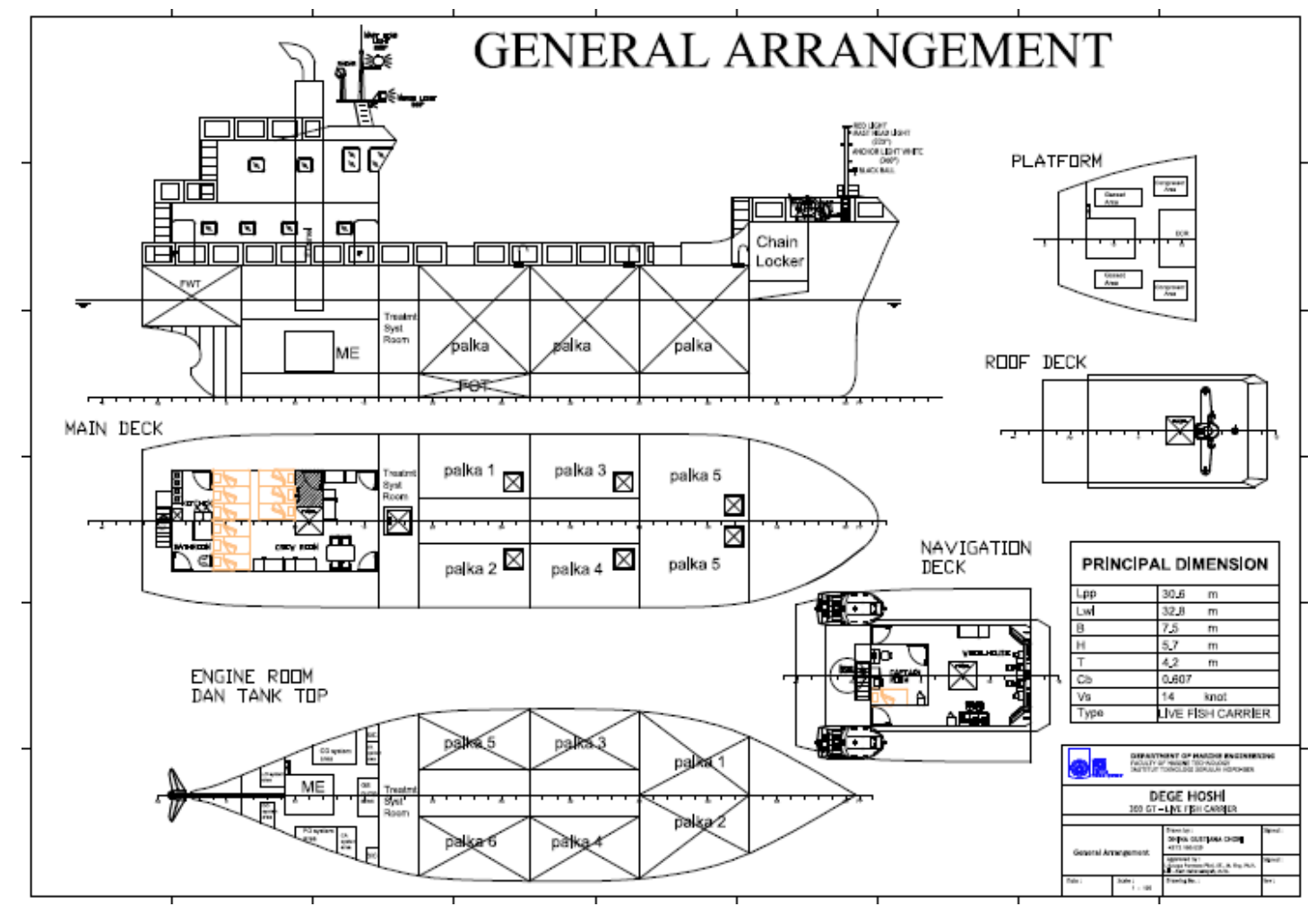

Gambar 1. General arragement kapal pengangkut ikan

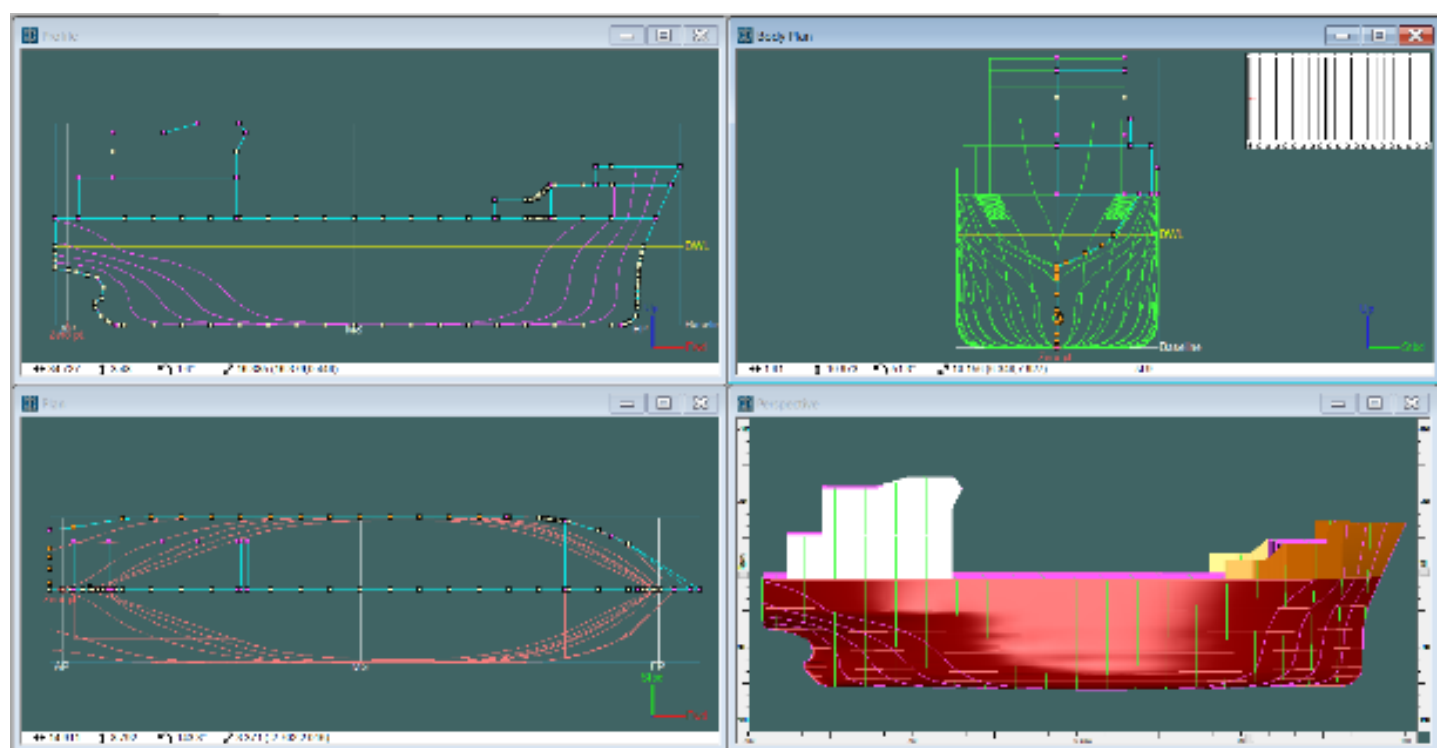

Gambar 2. Maxsurf modeler kapal pengangkut ikan

\section{Pemodelan Tangki Kapal}

Setalah pemodelan lambung kapal selesai dan didapatkan gambar 3D kapal, maka dapat dibuat susunan peletakan tangki pada kapal sesuai dengan
GA yang telah ada. Pemodelan tangki kapal dilakukan menggunakan software Maxsurf Stability, yang mana hasil gambar pemodelan tangki kapal ditampilkan pada Gambar 3. 


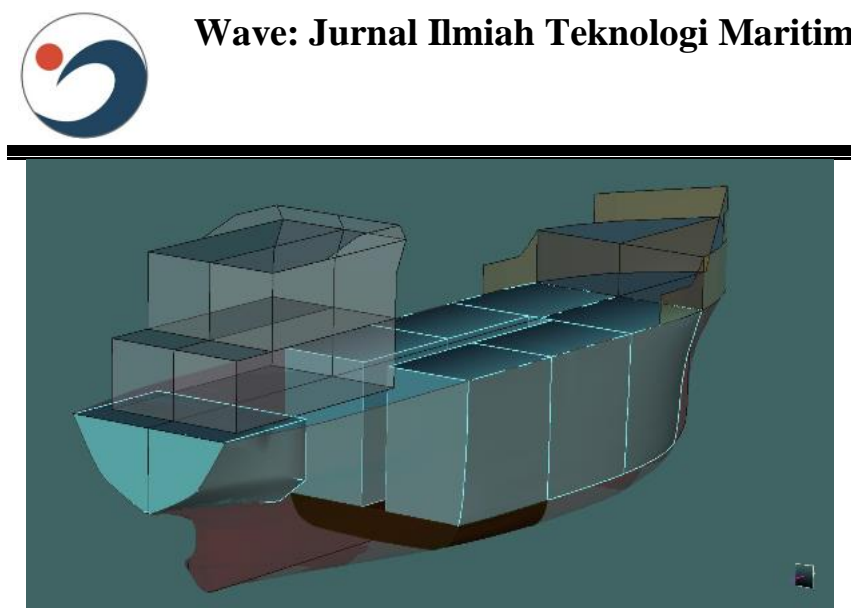

Gambar 3. Pemodelan tangki pada kapal ikan

\section{Simulasi Stabilitas Kapal}

Simulasi stabilitas kapal dilakukan menggunakan software Maxsurf Stability yang sebelumnya telah diberikan tangki-tangki yang akan dihitung stabilitasnya. Variabel yang akan divariasikan pada paper ini ada beberapa antara lain:

- Muatan pada ruang muat

Jumlah muatan pada ruang muat dibuat bervariasi mulai $0 \%$ muatan, $25 \%$ muatan, $50 \%$ muatan, $75 \%$ muatan dan $95 \%$ muatan.

- Muatan pada tangki

Jumlah muatan pada tangki, baik tangki air bersih (fresh water tank/FWT) dan tangki bahan bakar (fuel oil tank/FOT) dibuat bervariasi mulai 0\%, $25 \%, 50 \%, 75 \%$ dan $100 \%$ kapasitas volume tangki.

\section{Permukaan Bebas Kapal}

Menurut hasil penelitian (Ananda, 2017), efek permukaan bebas terjadi di dalam kapal apabila ada suatu permukaan cairan yang bergerak bebas. Ketika kapal mengalami oleng, permukaan cairan tersebut ikut bergerak bebas sehingga dapat menimbulkan gaya-gaya yang mengganggu kestabilan kapal. Perhitungan koreksi permukaan bebas dilakukan menggunakan rumus berikut:

$$
G G v=\left(N \times L \times \frac{B^{3}}{12} \times V\right) \times\left(\frac{\rho a t}{\rho a l}\right)
$$

Dimana:

GGv : Virtual Lost of the GM (m);

$\mathrm{N} \quad$ : Jumlah sekat (buah);

L : Panjang kompartemen (m);

B : Lebar kompartemen (m);
V : Volume kompartemen $\left(\mathrm{m}^{3}\right)$;
$\rho_{\text {at }} \quad$ : Massa jenis air tawar $\left(\mathrm{t} / \mathrm{m}^{3}\right)$;
$\rho_{\mathrm{al}} \quad$ : Massa jenis air laut $\left(\mathrm{t} / \mathrm{m}^{3}\right)$.

\section{Standar International Maritime Organization (IMO)}

IMO sebagai organisasi yang menangani tentang pelayaran dan berbagai industri yang bergerak di bidang kemaritiman telah mengeluarkan beberapa kriteria yang terkait dengan kapal antara lain tentang desain kapal, konstruksi, peralatan di kapal, operasi kapal dan sebagainya. Acuan tentang standar stabilitas kapal pada paper ini mengacu pada standar yang dikeluarkan oleh (IMO, 2008). Untuk kriteria yang diperhitungkan adalah sebagai berikut:

- 2.3 roll back angle;

- 3.1.2.4 initial GMt;

- 4.2.3.1 initial GMt for vessels $>=24 \mathrm{~m}$ in length;

- 2.2.4 Initial GMt;

- 2.1.3.1 initial GMt for vessels $>=24 \mathrm{~m}$ in length .

\section{HASIL DAN PEMBAHASAN}

\section{Perhitungan Berat Muatan}

Tabel 2. Total muatan ruang muat

\begin{tabular}{ccc}
\hline $\begin{array}{c}\text { Variasi } \\
\text { Muatan }\end{array}$ & $\begin{array}{c}\text { Volume } \\
\text { Ruangan }\end{array}$ & $\begin{array}{c}\text { Berat } \\
\text { Muatan }\end{array}$ \\
\hline $0 \%$ & $0 \mathrm{~m}^{3}$ & 0 ton \\
$25 \%$ & $111,40 \mathrm{~m}^{3}$ & 111,40 ton \\
$50 \%$ & $222,81 \mathrm{~m}^{3}$ & 222,81 ton \\
$75 \%$ & $334,22 \mathrm{~m}^{3}$ & 334,22 ton \\
$95 \%$ & $423,34 \mathrm{~m}^{3}$ & 423,34 ton \\
\hline
\end{tabular}

Tabel 3. Total muatan FWT

\begin{tabular}{ccc}
\hline $\begin{array}{c}\text { Variasi } \\
\text { Muatan }\end{array}$ & $\begin{array}{c}\text { Volume } \\
\text { Ruangan }\end{array}$ & $\begin{array}{c}\text { Berat } \\
\text { Muatan }\end{array}$ \\
\hline $25 \%$ & $55,47 \mathrm{~m}^{3}$ & 13,86 ton \\
$50 \%$ & $55,47 \mathrm{~m}^{3}$ & 27,73 ton \\
$75 \%$ & $55,47 \mathrm{~m}^{3}$ & 41,60 ton \\
$100 \%$ & $55,47 \mathrm{~m}^{3}$ & 55,47 ton \\
\hline
\end{tabular}




\begin{tabular}{ccc}
\hline \hline \multicolumn{3}{c}{ Tabel 4. Total muatan FOT } \\
\cline { 2 - 3 } $\begin{array}{c}\text { Variasi } \\
\text { Muatan }\end{array}$ & $\begin{array}{c}\text { Volume } \\
\text { Ruangan }\end{array}$ & $\begin{array}{c}\text { Berat } \\
\text { Muatan }\end{array}$ \\
\hline $25 \%$ & $31,80 \mathrm{~m}^{3}$ & 7,50 ton \\
$50 \%$ & $31,80 \mathrm{~m}^{3}$ & 15,01 ton \\
$75 \%$ & $31,80 \mathrm{~m}^{3}$ & 22,52 ton \\
$100 \%$ & $31,80 \mathrm{~m}^{3}$ & 30,03 ton \\
\hline
\end{tabular}

Untuk hasil perhitungan muatan pada ruang muat dan tangki, setelah dilakukan pemodelan tangki sesuai dengan guidance dari Bentley Maxsurf (2013) didapatkan untuk volume dan muatan air di ruang muat pada berbagai variasi ditampilkan pada Tabel 2 .

Untuk volume dan barat muatan di tangki FWT dan tangki FOW pada berbagai variasi ditampilkan pada Tabel 3 dan Tabel 4.

\section{Perhitungan Permukaan Bebas Kapal}

Untuk perhitungan permukaan bebas kapal dilakukan menggunakan persamaan (1) dimana pada kapal terdapat enam buah tangki ruang muat. Setelah dilakukan perhitungan nilai $\mathrm{GGv}$, maka hasil perhitungan ditabelkan pada Tabel 5 .

Tabel 5. Perhitungan GGv

\begin{tabular}{cccccc}
\hline Keterangan & $0 \%$ & $25 \%$ & $50 \%$ & $75 \%$ & $95 \%$ \\
\hline Palka 1 & 0 & 1.07 & 0.53 & 0.35 & 0.28 \\
Palka 2 & 0 & 1.07 & 0.53 & 0.35 & 0.28 \\
Palka 3 & 0 & 0.73 & 0.36 & 0.24 & 0.19 \\
Palka 4 & 0 & 0.73 & 0.36 & 0.24 & 0.19 \\
Palka 5 & 0 & 0.73 & 0.36 & 0.24 & 0.19 \\
Palka 6 & 0 & 0.73 & 0.36 & 0.24 & 0.19 \\
\hline
\end{tabular}

\section{Analisa Kriteria Stabilitas IMO}

Tabel 6. Kriteria stabilitas muatan $0 \%$

\begin{tabular}{lcccccc}
\multicolumn{1}{c}{ Criteria } & $25 \%$ & $50 \%$ & $75 \%$ & $100 \%$ & $\begin{array}{l}\text { Value } \\
\text { from } \\
\text { IMO }\end{array}$ \\
\hline 2.3: IMO Roll back angle & 21.2 & 20.5 & 20.0 & 17.5 & Deg \\
3.1.2.4: Initial GMt & Pass & Pass & Fail & Pass & $>0.150$ \\
4.2.3.1: Initial GMt for & Fail & Fail & Fail & Pass & $>0.350$ \\
vessels $>=24 \mathrm{~m}$ in length & & & & & \\
2.2.4: Initial GMt & Pass & Pass & Fail & Pass $>0.150$ \\
$\begin{array}{l}\text { 2.1.3.1: Initial GMt for } \\
\text { vessels }>=24 \mathrm{~m} \text { in length }\end{array}$ & Fail & Fail & Fail & Pass & $>0.350$ \\
\hline
\end{tabular}

Tabel 7. Kriteria stabilitas muatan $25 \%$

\begin{tabular}{lcccccc}
\hline \multicolumn{1}{c}{ Criteria } & $25 \%$ & $50 \%$ & $75 \%$ & $100 \%$ & $\begin{array}{l}\text { Value } \\
\text { from } \\
\text { IMO }\end{array}$ \\
\hline $\begin{array}{l}\text { 2.3: IMO Roll back angle } \\
\text { 3.1.2.4: Initial GMt }\end{array}$ & 18.9 & 19.3 & 19.5 & 18.1 & Deg \\
$\begin{array}{l}\text { 4.2.3.1: Initial GMt for } \\
\text { vessels }>=24 \mathrm{~m} \text { in length }\end{array}$ & Fail & Fail & Fail & Fail & Pass & $>0.150$ \\
2.2.4: Initial GMt & Fail & Fail & Fail & Pass $>0.350$ \\
$\begin{array}{l}\text { 2.1.3.1: Initial GMt for } \\
\text { vessels }>=24 \mathrm{~m} \text { in length }\end{array}$ & Fail & Fail & Fail & Pass $>0.150$ \\
\hline
\end{tabular}

Setelah perhitungan berat muatan diketahui maka langkah selanjutnya adalah melakukan analisa kriteria stabilitas sesuai dengan guidance dari Bentley
Maxsurf (2013). Pada kriteria stabilitas ini variasi dilakukan mengikuti variasi pada ruang muat yaitu $0 \%, 25 \%, 50 \%, 75 \%$ dan $95 \%$, dimana pada setiap variasi tersebut volume tangki FWT dan FOT juga divariasikan yaitu $25 \%, 50 \%, 75 \%$ dan $100 \%$.

Tabel 8. Kriteria stabilitas muatan $\mathbf{5 0 \%}$

\begin{tabular}{|c|c|c|c|c|c|c|}
\hline Criteria & $25 \%$ & $50 \%$ & $75 \%$ & $100 \%$ & & $\begin{array}{l}\text { Value } \\
\text { from } \\
\text { IMO }\end{array}$ \\
\hline 2.3: IMO Roll back angle & 19.3 & 19.3 & 19.2 & 17.9 & & Deg \\
\hline 3.1.2.4: Initial GMt & Fail & Pass & Pass & Pass & $>$ & 0.150 \\
\hline $\begin{array}{l}\text { 4.2.3.1: Initial GMt for } \\
\text { vessels }>=24 \mathrm{~m} \text { in length }\end{array}$ & Fail & Fail & Fail & Pass & $>$ & 0.350 \\
\hline 2.2.4: Initial GMt & Fail & Pass & Pass & Pass & $>$ & 0.150 \\
\hline $\begin{array}{l}\text { 2.1.3.1: Initial GMt for } \\
\text { vessels }>=24 \mathrm{~m} \text { in length }\end{array}$ & Fail & Fail & Fail & Pass & $>$ & 0.350 \\
\hline
\end{tabular}

Tabel 9. Kriteria stabilitas muatan $\mathbf{7 5 \%}$

\begin{tabular}{lcccccc}
\hline \multicolumn{1}{c}{ Criteria } & $25 \%$ & $50 \%$ & $75 \%$ & $100 \%$ & $\begin{array}{c}\text { Value } \\
\text { from IMO }\end{array}$ \\
\hline 2.3: IMO Roll back angle & 19.0 & 18.8 & 18.7 & 18.7 & $>$ & 21.2 \\
3.1.2.4: Initial GMt & Fail & Pass & Pass & Pass & $>0.150$ \\
4.2.3.1: Initial GMt for vessels & Fail & Fail & Fail & Pass & $>0.350$ \\
>=24 m in length & & & & & & \\
2.2.1: Area 0 to 30 & Pass & Fail & Pass & Pass & $>3.1513$ \\
2.2.4: Initial GMt & Fail & Pass & Pass & Pass & $>0.150$ \\
2.1.3.1: Initial GMt for vessels & Fail & Fail & Fail & Pass & $>0.350$ \\
$>=24 \mathrm{~m}$ in length & & & & & & \\
\hline
\end{tabular}


Tabel 10. Kriteria stabilitas muatan $95 \%$

\begin{tabular}{|c|c|c|c|c|c|}
\hline Criteria & $25 \%$ & $50 \%$ & $75 \%$ & $100 \%$ & $\begin{array}{c}\text { Value } \\
\text { from IMO }\end{array}$ \\
\hline 2.3: IMO Roll back angle & 22.0 & 18.8 & 18.6 & 18.6 & Deg \\
\hline 3.1.2.1: Area 0 to 30 & Fail & Fail & Fail & Pass & $>3.1513$ \\
\hline 3.1.2.1: Area 0 to 40 & Fail & Fail & Pass & Pass & $>5.1566$ \\
\hline 3.1.2.1: Area 30 to 40 & Fail & Pass & Pass & Pass & $>1.7189$ \\
\hline 3.1.2.3: Max GZ at 30 or greater & Fail & Pass & Pass & Pass & $>0.200$ \\
\hline 3.12.4: Initial GMt & Fail & Fail & Fail & Pass & $>0.150$ \\
\hline 4.2.3.1: Intial GMt for vessels $>=24 \mathrm{~m}$ in length & Fail & Fail & Fail & Pass & $>0.350$ \\
\hline
\end{tabular}

Hasil dari analisa kriteria stabilitas menurut (IMO, 2008) ditampilkan pada Tabel 6, Tabel 7, Tabel 8, Tabel 9 dan Tabel 10.

\section{Pembahasan}

Dari tabel kriteria stabilitas yang ditampilkan maka dapat diperoleh informasi untuk kapal pengangkut ikan tersebut pada kondisi muatan 0\% sesuai dengan Tabel 6 maka kapal dengan volume FWT dan FOT $\leq 75 \%$ dinyatakan tidak memenuhi kriteria stablitas. Untuk kondisi muatan $25 \%$ sesuai dengan Tabel 7 maka kapal dengan volume FWT dan FOT $\leq 75 \%$ dinyatakan tidak memenuhi kriteria stabilitas. Untuk kondisi muatan 50\% sesuai dengan Tabel 8 maka kapal dengan volume FWT dan FOT $\leq 75 \%$ dinyatakan tidak memenuhi kriteria stabilitas. Untuk kondisi muatan $75 \%$ sesuai dengan Tabel 9 maka kapal dengan volume FWT dan FOT $\leq 50 \%$ dinyatakan tidak memenuhi kriteria stabilitas. Dan untuk kondisi muatan 95\% sesuai dengan Tabel 10 maka kapal dengan volume FWT dan FOT $\leq 75 \%$ dinyatakan tidak memenuhi kriteria stabilitas.

\section{KESIMPULAN}

Kesimpulan yang dapat diambil pada paper ini adalah untuk kapal pengangkut ikan dengan tipe ini kriteria stabilitas menurut IMO pada kondisi muatan $0-95 \%$ dengan volume FWT dan FOT $\leq 75 \%$ dinyatakan tidak layak, sedangkan untuk volume FWT dan FOT 100\% dinyatakan layak. Kondisi ini disebabkan karena pada volume FWT dan FOT $\leq 75 \%$ kapal mengalami kondisi tidak seimbang, lebih berat pada bagian depan (trim by bow). Untuk nilai GGv memiliki kecenderungan rendah jika volume ruang palka muatannya mendekati penuh.

\section{DAFTAR PUSTAKA}

Ananda, N. D., 2017. Desain Ruang Muat Kapal Ikan Hidup Menggunakan Sistem Tertutup pada Kapal 300 GT. Laporan Akhir. Institut Teknologi Sepuluh Nopember, Surabaya.

Bentley Maxsurf, 2013. Maxsurf Stability, in: Bentley Systems Incorporated. pp. 1-6.

IMO, 2008. Adoption of the International Code on

Intact Stability, International Maritime Organization, London. https://doi.org/10.1126/science.202.4366.409

Kristiyono, T. A. dan Azhar, A., 2017. Kajian Eksperimental Stabilitas Kapal Kecil di Lamongan. Laporan Penelitian. Surabaya: LPPM Universitas Hang Tuah.

Kusyairi, Hayati, N. dan Madyowati, S. O., 2013. Efektivitas Sistem Transportasi Kering Tertutup pada Pengangkutan Benih Lele Dumbo (Clarias Gariepinus). Jurnal Agroknow, Vol. 1 (1): 39-45.

Mujahid, A. S. dan Priohutomo, K., 2018. Studi Kelayakan Desain Kapal Hisap Tambang. Wave: Jurnal Ilmiah Teknologi Maritim, Vol. 12 (2): 81-88.

Novita, Y., 2011. Pengaruh Free Surface terhadap Stabilitas Kapal Pengangkut Ikan Hidup. Buletin PSP, Vol. 19 (2): 35-43.

Novita, Y., Martiyani, N dan Ariyani, R. E., 2014. Kualitas Stabilitas Kapal Payang Pelabuhan Ratu Berdasarkan Distribusi Muatan. Jurnal IPTEKS PSP, Vol. 1 (1): 28-39.

Waluyo, Leksono, S. dan Santosa, M. G., 2018. Karakteristik Sea Keeping Kapal Angkut Ikan 60 GT di Sebaran Wilayah Perikanan Perairan Indonesia. Wave: Jurnal Ilmiah Teknologi Maritim, Vol. 12 (2): 89-94. 
Pengaruh Volume Air di Ruang Muat terhadap Stabilitas Kapal Pengangkut Ikan Hidup (Randy Hedva Rakasiwi Rumbawa, Ali Azhar dan Kusnindar Priohutomo)

HALAMAN KOSONG 